\title{
Transformaciones de Santiago de Chile 1960 - 1980. La manzana de la ciudad interior.
}

Transformations of Santiago de Chile from 1960 to 1980. The inner city block.

Jonás Figueroa Salas

\section{Filiación}

Arquitecto U. de Chile, Técnico Urbanista INAP, Profesor Titular USACH.

\section{Resumen}

Este escrito presenta reflexión sobre cuatro grandes operaciones que pueden ser consideradas, a nuestro entender, los pilares sobre los que se funda la acción urbanística y arquitectónica que se realiza a lo largo del tercer cuarto del siglo XX. Es éste un período con avances y retrocesos, creativo y traumático para la historia social y económica del país y también para la historia de la ciudad.

\section{Palabras clave}

Plan B. Vicuña Mackenna; Plan Brunner; Plan Honold - Parrochia; Unidad Vecinal Portales; Edificio Diego Portales (Gabriela Mistral), Remodelación San Borja; Urbanismo en Santiago de Chile.

\section{Abstract}

This paper presents reflections on four main operations that can be considered, in our opinion, the pillars on which rests the town-planning and architecture that is done during the third quarter of the century. Is this a period with advances and setbacks, creative and traumatic for the social and economic history of the country and also for the history of the city.

\section{Key words}

Vicuña Mackenna Plan; Brunner Plan; Honold and Parrochia Plan; Neighborhood Unit Portales; Diego Portales building (Gabriela Mistral); remodeling San Borja; Urbanism in Santiago de Chile.

\section{Sumario}

1 El problema

2 Las hipótesis

3 El desplazamiento escalar de la planificación urbana

4 El arterialismo de la obra pública

5 Recomposición morfológica del tejido urbano de las zonas de borde

6 Descomposición tipológica del tejido urbano

7 Las preguntas

Bibliografía temática 


\section{El problema}

Este escrito no es un recuento, ni siquiera el registro de una época particular de la historia del desarrollo urbano de la ciudad de Santiago de Chile. Faltaría tiempo y volumen para abarcar todo lo que una ciudad expresa en el día a día y en cada ocasión que la sociedad se otorga oportunidades para transformar el aparato físico en un organismo en permanente desarrollo. Por el contrario, este escrito sólo se propone como una reflexión sobre cuatro grandes operaciones que pueden ser consideradas, a nuestro entender, los pilares sobre los que se funda la acción urbanística arquitectónica que se lleva a cabo a lo largo del tercer cuarto del siglo $X X$. Es éste un período particular, con avances y retrocesos, creativo y traumático para la historia social y económica del país y también para la historia de la ciudad. En el ámbito urbanístico arquitectónico se producen cambios radicales en los modos de hacer y entender los contenidos técnicos y en las escalas de actuación, a través del desarrollo de obras que modificarán la estructura urbana y las dinámicas de usos del suelo.

Las cuatro operaciones que reflejan estos veinte años en la vida activa y pasiva de la ciudad en general y de la ciudad interior, en particular, tienen que ver con los siguientes fenómenos:

- Desplazamiento escalar de la planificación urbana;

- Arterialismo como expresión de las grandes obras públicas;

- Recomposición morfológica del tejido urbano de las zonas de borde; y

- Descomposición tipológica del tejido urbano de las zonas interiores.

Las primeras dos operaciones se derivan de cambios que se producen en las metodologías de la técnica urbanística y las dos restantes se relacionan con la aplicación de ideas importadas por la práctica arquitectónica. El desplazamiento... se observa a lo largo de la revisión de los documentos previos que avalan la formulación del Plano Intercomunal de Santiago de 1960 y de la experiencia internacional acerca del urbanismo regionalista. El arterialismo... en la obra pública se pone en evidencia en la revisión de tres documentos históricos que marcan a su vez, tres momentos de esplendor del urbanismo chileno: el plan de B. Vicuña Mackenna, el plano de K. H. Brunner y el plano de J. Honold y J. Parrochia. La recomposición y descomposición... que experimenta morfológica y tipológicamente la manzana, surgen de operaciones de corte arquitectónico y se derivan de modificaciones que experimenta el aparato construido. La importación de teorías y métodos de hacer urbanismo y arquitectura, sin mediar un tamiz que los traduzca a los esquemas locales del país, lleva a que unas y otros se apliquen a medias o se apliquen mal, generando nuevas temáticas y desafíos, asuntos aún pendientes para la profesión.

Entre los años 60 y 80 del siglo $X X$, estas cuatro operaciones constituyen y manifiestan un nuevo orden urbano que repercute en la organización espacial y en donde la manzana ${ }^{1}$, en cuanto bloque construido y unidad vecinal, es el artefacto físico que experimenta las mayores transformaciones. Debiendo ser el módulo y la unidad de intervención tanto en las zonas consolidadas como en las áreas de nueva urbanización, la manzana es un objeto discordante para el nuevo urbanismo y la nueva arquitectura que se práctica tempranamente en los años 50 y con mayor intensidad a lo largo de los 60 y 70 . Hasta ese momento, la manzana es el único elemento del aparato físico que posibilita que los cambios de una ciudad a otra, de

\footnotetext{
1 Espacio urbano, edificado o destinado a la edificación, generalmente cuadrangular, delimitado por calles por todos sus lados. RAE, 2006
} 
la ciudad colonial a la republicana y de ésta a la ciudad ilustrada se hubiesen llevado a cabo sin desenlaces traumáticos. Los cambios que operan en el período en estudio sobre la manzana, como artefacto físico y también social, receptáculo de innumerables acumulaciones históricas, incide en nuevos modos de percibir y ocupar el espacio habitado.

El período termina con el surgimiento de una reacción postmodernista, que se expresa como la desregulación de las determinaciones urbanísticas y como un compositivismo arquitectónico cuyos contenidos no pasan más allá de un manifiesto barroco $^{2}$. Este último caso, puede ser entendido como el intento de superar los paradigmas fundamentales del Movimiento Moderno.

\section{Las hipótesis}

El nuevo orden urbano impuesto por los cambios que se operan a partir de mediados los años cincuenta del siglo XX, se expresa en la ciudad interior, que es lo mismo que decir la comuna de Santiago de Chile, como transformaciones radicales sobre el aparato físico de la ciudad. Estas transformaciones pueden ser clasificadas como operaciones de composición, recomposición y descomposición de la morfología y la tipología del tejido urbano y de su elemento aglutinador, la manzana. Las hipótesis que iluminan esta exploración sobre los detonantes y los efectos de este nuevo orden urbano, podrían ser enunciadas del siguiente modo:

1. El hacer urbanístico y arquitectónico puesto en práctica en los años 60, repercute y altera la organización espacial de la gran y pequeña escala de la ciudad interior; $y$

2. El nuevo orden que surge de esta organización espacial, modifica e introduce nuevos elementos configurantes de la morfología y tipología del tejido urbano.

Desde los años 40, la ciudad interior ya se encuentra prácticamente consolidada y sin grandes reservas de suelo urbanizable. Cualquier nuevo crecimiento físico o nueva obra urbana que se registra durante la segunda mitad del siglo $X X$, debe realizarse principalmente en polígonos de terrenos emplazados en la primera corona de la ciudad republicana, en terrenos vinculados con el aparato productivo y con los sistemas de transporte ferroviario. La segunda modalidad, es el desarrollo en áreas de áreas de renovación. A la fecha ya existían antecedentes en la materia con la recuperación para usos urbanos, de los trazados del ferrocarril a Puente Alto y la posterior construcción del Parque Bustamante, cuyo diseño original es obra del arquitecto vienés Karl $\mathrm{H}$. Brunner. Asimismo, esta última acción es demostrativa del papel que asumen los parques urbanos como factores de cualificación de zonas deprimidas por los usos relacionados con los trazados infraestructurales.

Posteriormente, el interés de los organismos públicos con atribuciones y competencias en los asuntos urbanísticos -Ministerio de Obras Públicas, principalmente- vuelcan su atención de modo primordial, hacia la escala regional. No en vano, uno de los avances del Plan Intercomunal de Santiago de 1960, se denomina Plano Micro - Regional y la provincia de Santiago sobre cuyo territorio tiene sus afecciones, se denomina Región IV-B. Un ejercicio institucional y teórico discontinuo y la falta de una reflexión y debate público, promueve que el período transite en términos de planificación, desde una urbanística de corte regionalista

\footnotetext{
2 Llamamos compositivismo a las propuestas que surgen en los ochenta y noventa para dar un giro al discurso funcionalista del Movimiento Moderno. Rob Krier y Aldo Rossi son algunos de los arquitectos que lideran este reaccionismo, quienes proponen un retorno a los orígenes neoclásicos y en donde la calle y la plaza tiene un protagonismo en la estructura urbana. En Chile, este reaccionismo es llevado adelante por arquitectos que difundían sus propuestas a través de la revista ARS.
} 
hasta la práctica desregulación de los instrumentos de planificación, al final de los años 70, mediante la aplicación de un decreto ley que anula los límites urbanos de la ciudad. Se supone, erróneamente, que el suelo no es un recurso escaso y que la aplicación de restricciones legales incide en el alza de los precios de la vivienda. En la práctica, esta desregulación no se traduce ni en una reducción de los costos de acceso a la vivienda, ni tampoco logra resolver los conflictos relacionados con la producción del suelo urbano.

\section{El desplazamiento escalar de la planificación urbana}

El urbanismo de escala comunal propuesto y desarrollado por Karl Brunner y sus asesores locales, formulado para la ciudad interior, se muestra incapaz por su propia lógica de ordenar un crecimiento físico que, la mayoría de las veces, llega de la mano de la propia acción de los organismos públicos. En el interés de resolver los problemas de vivienda de amplios sectores de la población, se ocupa el extrarradio rural que presenta menores dificultades financieras y técnicas de producción. A pesar del conocimiento y la certeza de los resultados y limitaciones de este modelo de hacer ciudad, esta acción gubernamental ha recorrido toda la segunda mitad del siglo XX.

Sin embargo, son las propias preocupaciones de Brunner acerca de la vialidad del perímetro de la ciudad, las que anuncian que la urbanística de escala comunal debe dar paso a otros instrumentos que resuelvan los problemas generados por el crecimiento extensivo que ya en los años 30, comenzaba a producirse tempranamente en Santiago. Aspecto que es demostrable con el tratamiento que se plantea para las áreas de borde de la ciudad construida.

Luego, Luis Muñoz Maluschka en su calidad de heredero directo de los modos de entender los problemas de la ciudad de K. H. B., tomará el testigo del urbanismo y la planificación de naturaleza regionalista. Cuestión que queda en evidencia en los trazados viales en anillo propuestos para orientar el crecimiento extensivo de la ciudad. Junto a ello, las dinámicas de movimientos de población desde las áreas centrales de Santiago hacia zonas rurales y la ingente llegada de población inmigrante desde las provincias, se expresa en la ciudad interior como un deterioro de las zonas residenciales vacantes y el crecimiento de la corona exterior a través de urbanizaciones de tipo residencial -llamadas poblaciones- llevadas a cabo por la Caja de Seguro Obrero Obligatorio en los años 20, la Caja de Habitación Popular, a partir de $1936^{3}$, y la Caja de Habitación, en los años 40.

Por aquellos mismos años, se asiste al surgimiento de barrios residenciales para población de altos recursos en la banda oriental de la ciudad, cuya expresión física y paisajística pretende inspirarse en las experiencias de las ciudades jardín inglesas, que toman como modelo las ideas propugnadas por Ebenezer Howard. Al final, estos desarrollos locales ni tienen el mismo sentido social ni menos constituyen operaciones urbanísticas de la trascendencia de las que se llevan a cabo en las ciudades europeas y norteamericanas.

Con el fin de ejercitar la comprensión de los cambios que operan en las nuevas ideas urbanísticas de los años 60 del siglo XX y los nuevos órdenes que surgen después de ello, debemos viajar a lo más profundo de las teorías urbanísticas. El urbanismo regionalista que ampara gran parte de los contenidos de los dos instrumentos de planeamiento formulados en el período, el Plano Microregional de

\footnotetext{
3 Bajo este sistema de ahorro se construyen las poblaciones Vivaceta, Pedro Montt y Arauco, entre otras. Al respecto, ver VIOLICH, Francis: Cities of Latin America. Reinhold Publishing Corporation, New York, 1944, chapter 6.
} 
1958 y el Plano Intercomunal de 1960, se encuentra inserto en los movimientos de carácter socialista del siglo XVIII. Entre éstos, son valederas las ideas y las experiencias utópicas llevadas a cabo a lo largo del milochocientos por Saint Simón, Owen, Fourier y Cabet, quienes perseguían la superación de los problemas que evidenciaba la ciudad de la época mediante proyectos sociales emplazados en áreas rurales. El campo o espacio rural, en lo posible dedicado a actividades agrícolas, surge como un soporte ideal a la hora de pensar un contexto deseable que permita la salida de la sociedad de los problemas y conflictos sociales y ambientales causados por los sistemas productivos fabriles, que se instalan en las grandes ciudades desde tiempos de la revolución industrial.

Ya más próximos a nuestro tiempo, son teóricos y pensadores americanos los que en un intento de progresismo, proponen allá por la segunda y tercera década del siglo XX, la reforma de la ciudad y la construcción de un Estado moderno, inserto en el New Deal promovido desde las instituciones gubernamentales. Su intención se dirige a la resolución de las limitaciones y los conflictos promovidos por el estilo conocido como la urban - industrial América: contaminación, congestión, insalubridad, explotación de la clase obrera, malas condiciones de vida, etc., mediante la fundación de núcleos urbanos en los extrarradios rurales y agrícolas de las grandes ciudades tales como Nueva York, Chicago y Filadelfia. Un buen número de estos nuevos asentamientos emplazados en el ámbito rural es de naturaleza obrera, con expresiones edilicias y urbanísticas derivadas de las experiencias inglesas ideadas por el citado Howard a fines del siglo XIX y aplicadas por los arquitectos Barry Parker y Raymond Unwin en Letchworth y Hampstead a inicios del siglo $\mathrm{XX}^{4}$.

La diferencia entre una y otra experiencia, es que la americana pone el acento en el desarrollo del espacio regional mediante la creación de pequeños núcleos urbanos. La chilena, por su parte, pone acento en la ocupación del espacio regional en función de las demandas del Gran Santiago y en donde los núcleos satélites son anexados rápidamente por el crecimiento físico explosivo de la ciudad matriz.

El Seminario de Problemas del Gran Santiago, organizado por la Universidad de Chile a lo largo de 1957, se dedica a inventariar los conflictos que experimenta la ciudad a través del trabajo de diez comisiones. Estas se abocan a reflexionar sobre temas tan diversos como proyecciones de crecimiento, problemas de orden social y sanitario, producción, empleo y vivienda, entre otros. La segunda etapa del seminario, realizada al año siguiente, acoge la presentación de los resultados de trabajo de comisiones y cuyas principales recomendaciones se dirigen a desplazar la atención de los organismos y de los instrumentos hacia la escala regional ${ }^{5}$. En este evento, la región es entendida como zona de influencia de la gran ciudad, más que como un sistema territorial con sus propias sustancias y capacidades de carga y acogida. Este es el punto de partida del crecimiento físico explosivo que experimenta Santiago de Chile, agravado a través del tiempo por la carencia de los bienes y los equipamientos que requiere una gran ciudad y que por ello, resulta más extensa de lo que realmente es. Todo ha sido instalado fuera del ámbito de vida del ciudadano, en cualquiera y ninguna parte.

\footnotetext{
4 El sociólogo Lewis MUMFORD es uno de los principales defensores del urbanismo regionalista. Al respecto, ver Dal Co, Francesco: De los parques a la región. En La ciudad Americana, Editorial G. Gili, Barcelona, 1975, pág. 291.

5 El planeamiento de cualquier ciudad, además del estudio del área propiamente urbana, debe ser necesariamente dirigido a la región en que dicha ciudad se encuentra: de ella provienen los materiales en su estructura, de ella provienen los abastecimientos para la vida de sus habitantes y ella le proporciona el marco de su paisaje caracterizador. HONOLD, Juan: Visión general de los problemas del Gran Santiago. En Boletín Informativo N 34, Departamento de Extensión Cultural, Universidad de Chile, 1958. En los años 30, La Carta de Atenas afirmaba que ...la ciudad es la expresión geográfica y económica de la región...
} 
Los debates y las reflexiones llevadas a cabo a lo largo de los años cincuenta, el ya mencionado Seminario de Problemas del Gran Santiago y la presencia activa de importantes arquitectos en diferentes direcciones del Ministerio de Obras Públicas, desembocan en la formulación del primer plan que se propone regular los crecimientos extensivos del perímetro consolidado, siguiendo los ejes de acceso regional, y por ello, orientar los desarrollos del extrarradio regional de Santiago, Plan Intercomunal de Santiago de 1960. Las demostraciones fehacientes de este regionalismo urbanístico o urbanismo regionalista, comparecen en la ciudad interior a través del desarrollo de grandes obras públicas.

\section{El arterialismo de la obra pública}

Los asuntos relacionados con la vialidad son preocupaciones que vinculan los tres principales estadios de la urbanística chilena, que para ser más directos, podríamos denominar con los nombres de los que promueven y aplican los cambios: la ciudad republicana de Vicuña Mackenna; la ciudad ilustrada de Brunner y la ciudad región de J. Honold y J. Parrochia. Hoy en día, la vialidad y el transporte siguen siendo los principales problemas urbanos con los cuales deben lidiar las autoridades y los técnicos.

En tiempos de Benjamín Vicuña Mackenna, los factores motivantes fueron la mejora de las condiciones de vida de una ciudad que siendo capital de la República, no exhibía la imagen y los valores edilicios propios de una ciudad matriz, al estilo de los centros urbanos europeos, ni tampoco siquiera registraba el nivel de ornato $e$ higiene que ya observaban Buenos Aires y Río de Janeiro, ejemplares urbanos que servirán para motivar desde las instancias públicas y privadas la necesidad de disponer de un plan que promueva y oriente proyectos de transformación urbana y se constituya en la expresión ciudadana del periodo republicano. Sus viajes por una Europa urbana en obras, le acercan a las experiencias que se llevan a cabo en el París de Eugéne Haussmann, en la Barcelona de Ildefonso Cerdá y en el Madrid de Carlos María de Castro, en la segunda mitad del siglo XIX. En tal sentido, es posible observar en las propuestas contenidas en el Proyecto de Mejoras de Santiago, que actúa como un programa de gobierno -ejemplar aún hoy en día para los ciudadanos que se presentan a cargos municipales electos- temas de interés posibles de rastrear en el Central Park de F.L. Olmsted, y en la vialidad y el carácter de calle paseo o boulevard de Haussmann, entre otras cercanías y referencias.

La condición arterialista presente en el Plan General de Mejoras de la Capital (1872), formulado en la toma de posesión del cargo de intendente, Benjamín Vicuña Mackenna expone las modalidades de resolución de la pavimentación y apertura de nuevos trazados viales, y del diseño y construcción del Camino de Cintura, que constituye la primera vía anular de la ciudad, sin dejar de lado sus preocupaciones paisajísticas y de obras de canalización hidráulica.

$A$ inicios de los años 30 del siglo $X X$, se produce el segundo periodo de esplendor de la urbanística chilena. La llegada del arquitecto vienés Karl H. Brunner es la expresión de la voluntad institucional de conferirle algún grado de tecnicismo y legalidad a la acción pública sobre la ciudad y su desarrollo. Los costos en vidas humanas y el desorden imperante en cuestiones de ocupación de suelo y construcción aconsejan a la autoridad competente a tomar cartas en el asunto. La primera impresión que tenemos de Brunner es la de un arquitecto interesado en el debate acerca de la forma urbana y la categorización del espacio construido. En su primera misión (1929 - 1930) Brunner aplica la sabiduría que le confiere la tradición urbanístico arquitectónica vienesa y se transforma, a $15 \mathrm{mil} \mathrm{km}$ de distancia, en un intérprete de la cultura del ringsstrasse, espectador privilegiado del 
hacer de Otto Wagner y de las actuaciones del municipio socialista en los desarrollos residenciales de los hofe.

En la segunda misión en Chile (1932 - 1934), Brunner se reinventa como un arquitecto - ingeniero interesado en resolver las demandas de desplazamiento de la población y en el papel que deben cumplir las arterias y los trazados viales para corregir los efectos de los crecimientos a saltos que denota la expansión física de la ciudad. Por ello, el carácter del estudio del plan regulador de escala comunal, aprobado con cambios el año 1939, se sustenta en los requerimientos impuestos por el transporte y la vialidad. Esta es la herencia que Brunner deja a su partida a Bogotá el año 1934 y que marca de arterialismo las actuaciones públicas de Luis Muñoz Maluschka en el Ministerio de Fomento en los años cuarenta y posteriormente, las de Juan Honold y Juan Parrochia en el Ministerio de Obras Públicas, en los años cincuenta.

En el caso de las áreas interiores del núcleo consolidado, los trazados de Brunner discurren a modo de axialidades casi ceremoniales, potenciando su naturaleza central; en las áreas perimetrales, estos trazados viales se proponen para resolver los vacíos que deja el crecimiento a saltos, en una acción parecida al bordado artesanal o el entramado textil ${ }^{6}$ y que es la materia que desarrolla posteriormente en Bogotá.

Años más tarde, el Departamento de Urbanismo del Ministerio de Fomento de la época, al mando del ya mencionado Muñoz Maluschka, formula acciones concretas para resolver los problemas de accesibilidad y de conexión requeridos por los nuevos crecimientos perimetrales que se extendían por las comunas de Santiago (de mayor extensión a la superficie que hoy abarca), Quinta Normal, San Miguel, Nuñoa, Providencia y Conchalí. Si bien estas propuestas no pasaron más allá de la fase de estudio y debate, no dejan de ser importante a la hora de transformarse en los primeros intentos de pensar la ciudad como una totalidad, mediante la formulación de instrumentos omnicomprensivos y de comenzar a pensar más allá del perímetro construido y consolidado de la época, saltándose la fragmentación que imponen los límites comunales ${ }^{7}$.

Los estudios y las propuestas urbanísticas, que no pasan más allá de la fase de acopio de información y de avances, constituyen junto a los instrumentos legales, señales para comprender la construcción histórica del territorio. Estos instrumentos son demostrativos del crecimiento de la población, de las actividades productivas y de servicios, de los estándares de vida y también del consumo del suelo, necesario para alojar los nuevos desarrollos. Este consumo de suelo involucra el desarrollo de la industria de la construcción y también demanda necesidad de contar de documentos que regulen y promuevan el ordenamiento de las operaciones necesarias para disponer de un soporte físico idóneo.

La intención de dirigir la atención hacia el sentido arterialista de nuestra urbanística, es demostrar que el Plan Intercomunal de Santiago se expresa en la ciudad interior mediante nuevos trazados viales y nuevas oportunidades de transporte ferroviario, que considerando las demandas intercomunales de desplazamiento, inciden en la modificación de la estructura urbana y en la descomposición y posterior recomposición del tejido, manifestándose como cambios morfológicos que desplazan centralidades, generan nuevas axialidades y promueven áreas funcionales al servicio de las zonas centrales.

\footnotetext{
6 Al respecto, ver FIGUEROA, Jonás: 1929: la ciudad demostrativa. En Revista de Arquitectura Nº 8, $\mathrm{FAU} U \mathrm{UCH}$, 1996, pág.4 - 7.

7 VIOLICH, Francis: Op. Cit.
} 
La primera autopista urbana de Santiago, más conocida como avenida Norte Sur ${ }^{8}$, proyectada a fines de los años 50 y comenzada a construir diez años más tarde, surge como solución a la discontinuidad que observan las accesibilidades regionales norte sur, hasta ese momento carentes de trazado y facilidades. En la ciudad interior, esta vía discurre por un sector ocupado por usos industriales y zonas residenciales en deterioro. Fotografías de la época, señalan que este deterioro comenzaba a ser revertido al inicio de las obras viales mediante la renovación y densificación de los contenedores residenciales. Sin embargo, uno de los primeros de los muchos efectos de la arteria es la paralización de estas operaciones de renovación y el incremento del deterioro histórico del sector.

Las reflexiones que nos surgen por ello, tienen que ver con las limitaciones que observan las áreas centrales para desparramar su influencia e incidir en la renovación y transformación de sus zonas de borde, tal cual es la franja anexa de la autopista Norte Sur. Esta influencia de centralidad se extiende no más allá de una docena de manzanas y en donde la franja anexa a la autopista Norte Sur, se sitúa lejos de la misma, en un territorio que ni es dentro ni fuera del centro. El tejido de la manzana tipológico que expresa este centro de la ciudad interior, está compuesto por cuatro solares o seis predios. Mientras tanto, en las zonas de borde este tejido se compone de una mayor subdivisión predial, en función de los cursos de agua que discurren por el interior de los solares.

Esta condición de borde de la franja de la autopista urbana, se ha visto incrementada por las actuaciones públicas de peatonalización de las calles centrales y por el resurgimiento que observa el centro de la ciudad interior a partir de las inversiones privadas que lo han transformado en un potente atractor de funciones de escala metropolitana y sobre el cual convergen no menos de 2 millones de personas al día. Cifra para nada impactante si tenemos presente que sobre los terminales de transporte situados en la comuna de Estación Central, convergen en un inicio de fin de semana largo, no menos de 1 millón de personas. Estos dos millones de personas discurren por los atestados paseos Ahumada', Huérfanos y Estado, en una visión sorprendente incluso para el turista que viene de grandes centros urbanos como Paris, Madrid o Buenos Aires. Este resurgimiento del centro, ha venido a agregar a la condición de borde de la franja de la autopista Norte Sur, el carácter de zona de servicio o patio de luz por su facilidades de acceso desde la corta y larga distancia, en donde se alojan las actividades de bodegaje y almacenamiento de los insumos que requiere para su desarrollo el centro, ya sea aquel de usos financiero, administrativo o comercial. Para muestra un botón, los almacenes de una tienda por departamentos con varios locales en este centro, se instala la vera de la autopista. Este emplazamiento le permite abastecer con rapidez los locales de venta y presentar un acopio fluido desde los centros de producción a través de la autopista urbana.

La comprensión de esta situación y condición que marca tipológicamente ciertas zonas de la ciudad interior, permite definir operaciones necesarias para corregir los efectos indeseables que por una equivocada lectura del problema, se agravan al pensar que toda la ciudad debe ser una extensión de similar ornato y contenido. Estos necesarios patios de luz también es posible encontrarlos en París, Madrid y Buenos Aires. Entonces, ¿cuál es el tratamiento urbanístico posible y cuáles las operaciones deseables para estas piezas urbanas? y ¿cuál hubiese sido su carácter

\footnotetext{
8 También, LE CORBUSIER denomina Norte Sur a la primera autopista urbana de Buenos Aires en el Plan Director de 1938. La Arquitectura de Hoy No 4, 1947.

9 Ahumada es la calle más ancha del casco antiguo de la ciudad, $30 \mathrm{~cm}$. más. Aspecto justificable si por el lugar discurre el Camino del Inca. Ver VICUÑA MACKENNA, Benjamín: Páginas Escogidas. Editorial Universitaria, Santiago, 1987. pág. 225.
} 
y naturaleza de haberse llevado a cabo las obras propuestas por el concurso internacional de ideas del barrio centro poniente? ${ }^{10}$.

El ferrocarril metropolitano o Metro, es la segunda obra pública de gran formato que se hace presente en la ciudad interior de la mano del Plan Intercomunal de Santiago de 1960. A diferencia de los efectos que genera y recibe la Autopista Norte Sur, el Metro opera sobre la morfología urbana de modo indirecto y en donde su aparato físico cede el protagonismo al pasajero que llega y sale de la ciudad interior, especialmente sobre la estación Universidad de Chile. El Metro opera abasteciendo las vías peatonales en la nueva morfología de la ciudad. En los años 60, las principales vías que abastecían el centro, identificado en torno a la Plaza de Armas, discurrían por el interior de la trama vial. El Metro y el aumento del transporte público de superficie por la Alameda Bernardo O'Higgins han introducido el concepto de axialidad norte sur en la ciudad interior, inexistente en el aparato urbano de los años 60, más bien dependiente una morfología de centros, tales como la Plaza de Armas el antiguo Congreso, el Palacio de los Tribunales, etc., y de axialidades interiores, tales como las galerías comerciales situadas en las entrañas de las manzanas.

A su vez, ello también ha generado un desdoblamiento o mirror de la centralidad única de carácter religioso y comercial existente en el pasado. Hoy surge con gran fuerza, una centralidad de carácter civil en torno al Palacio de la Moneda y sus plazas y que ya presagia en su momento, el hacer urbanístico de Karl H. Brunner. Esta centralidad posee su propia axialidad, aunque por el momento y a diferencia del Paseo Ahumada, ésta se dirija hacia ninguna parte y no registre ningún elemento de la importancia histórica tal como posee la plaza mayor, hoy volcada hacia el espectáculo y el suceso como desencadenantes de situaciones espaciales. El paseo Ahumada es una axiliadad con una puerta en la Alameda (ipuerta del sol?), y un remate en la Plaza de Armas; el Palacio de la Moneda es una centralidad con una axiliadad sin inicios ni remates concretos que se constituyan en los atractores de actividades y de flujos peatonales permanentes. Sus presentes y futuros no pueden ser diferentes a los elementos ceremoniales, vacíos y semiabandonados a lo largo del día, pero altamente importante por su vacuidad a la hora del acto multitudinario y la manifestación pública.

Frente a esta articulación morfológica de axialidades y centralidades en sentido norte sur, la Alameda Bernardo O'Higgins no es más que una vía tangencial, que expulsa más que atrae actividades colectivas. Demasiada ancha para ser ocupada con las mismas intensidades en sus ambos bordes y en donde el lejos y el cerca tienen una dimensión diversa al lejos y al cerca de las vías que discurren en sentido norte sur, aunque a veces estas distancias sean menores. También, la pendiente levante poniente influye en la percepción y lectura de las distancias que configuran lo que entendemos como centro, haciendo que la bajada hacia el poniente alargue nuestro pasos y nos aleje, y la subida hacia el levante los acorte y transforme en larga lo que es corta distancia.

\footnotetext{
10 Área de remodelación en el centro de Santiago. En Revista Auca No 24/25, 1973. Al respecto, el arquitecto holandés Aldo VAN EYCK uno de los epónimos del Movimiento Moderno, forma parte del jurado internacional convocado para calificar un total de 87 proyectos provenientes de 25 países, que proponían la remodelación del sector afectado por la autopista Norte Sur, transformándolo en un centro proveedor de servicios metropolitanos. Los sucesos políticos acaecidos a partir de septiembre de 1973, impidieron el posterior desarrollo del proyecto. Debemos señalar que Van Eyck es un activo participante de los Congresos Internacionales de Arquitectura Moderna (CIAM).
} 


\section{Recomposición morfológica del tejido urbano de las zonas de borde}

Tal vez, uno de los actos más violentos en la historia urbanística de la ciudad del siglo XX, devino con la aplicación de los presupuestos del Movimiento Moderno y los efectos sobre el aparato físico que ello trajo consigo. Hasta ese momento, el tránsito histórico de una ciudad a otra, se produjo sin alterar mayormente la planta urbana sobre las que se asienta el grueso de los elementos configurantes de la ciudad: calles y manzanas, principalmente. Se modificaron los estilos, las alturas, los materiales y los sistemas constructivos, por citar aquellos elementos más caros al edificio. $Y$ cuando se produjeron cambios, el resultado dependía de operaciones de división de la horizontal o multiplicación de la vertical de la planta urbana. Pero, rara vez una nueva ciudad desconoció la ciudad que suplantaba: fachada continua y la calle como expresión y soporte del habitar urbano.

Aunque es posible rastrear actuaciones aisladas, cuarenta años después de divulgados los discursos fundacionales que pretendían traer "...corrientes de aire..."11 a la arquitectura y el urbanismo del siglo XX, se comienzan a aplicar en Chile los principales conceptos urbanísticos del Movimiento Moderno ${ }^{12}$. Situación que altera para siempre la ciudad de la segunda mitad del siglo XX. La planta urbana se modifica a partir de la aplicación de operaciones de sumatoria y sustracción de los contenidos de la manzana, en cuanto unidad física y en tanto módulo de configuración morfológica. A partir de ello, los espacios vacíos de la manzana que hasta ese momento estaban al servicio del edificio, se liberan y pasan a estar al servicio de la manzana, desconociendo las dimensiones y las escalas que utiliza el individuo para apropiarse del vacío restante.

En el interés de construir un relato y también un correlato urbanístico arquitectónico de los años 60, no podemos dejar de lado a aquellas acciones que pueden ser consideradas como pre-textos de lo que al final constituye la imagen definitiva de la ciudad. En este caso particular, nos interesa descubrir las claves para entender los proyectos de remodelación urbana realizados en la ciudad interior y que nos permiten descifrar los códigos de lo que por sí mismo resultan de complicada lectura.

Estos pre-textos nos lo brindan las obras de recuperación de áreas deterioradas por el arterialismo urbano presentada al concurso internacional para la Remodelación del Área del Centro de Santiago (CORMU, 1973). Concurso que también, se nos presenta como un modo de ponerse al día en lo que es ese momento transformaba a Santiago como una ciudad capital reacia al desarrollo de obras demostrativas del estilo o los estilos representativos de la modernidad. Ciudades como Buenos Aires y Río de Janeiro ya contaban con estos urbanismos y estas arquitecturas desde los años 40; Caracas, desde los años 50. Brasilia como la mayor expresión urbanística del Movimiento Moderno junto a Chandigarh, es de mediados los años $50^{13}$.

\footnotetext{
11 Comentario que hace Donat A. AGACHE al Prefecto de Río de Janeiro cuando recibe la visita de Le Corbusier (1929). Citado por LE CORBUSIER: Precisiones. Editorial Poseidón, Barcelona 1978. pág. 261.

12 La propuesta era situar los ámbitos de vida en una atmósfera verde, en donde los edificios tuviesen las suficientes facilidades y calidades de ventilación y asoleamiento. Los efectos ambientales nocivos que incorporó la industrialización de los procesos productivos y su inserción urbana en la ciudad europea, motivó amplios movimientos de rechazo y propuesta para resolver dichos conflictos que repercutían sobre la salud de las personas y la habitabilidad de los recintos.

13 El arquitecto napolitano Francesco VENEZIA, profesor en Venecia, afirma que América del Sur es el territorio ideal para la arquitectura de Le Corbusier. Este dato aumenta el cuestionamiento de la tardanza que sufren los postulados urbanísticos arquitectónicos del Movimiento Moderno en Chile. Ver en Hidalgo, Aldo: Francesco Venezia: temas de arquitectura. Revista ARTEOFICIO No 4, Escuela de Arquitectura USACH, 2006, pág. 47 - 51.
} 
Nos interesa el análisis de obras de gran formato, en los cuales la manzana se desempeña como módulo y escala de intervención. En los casos que los postulados tienen una aplicación parcial, las áreas centrales afectadas registran una tendencia a la suburbanización. Más aún si la normativa aplicada en las mismas, permitía la aplicación del concepto de antejardín, haciendo desparecer por ello el concepto de la calle corredor o calle túnel, tal como la llama Le Corbusier en la presentación de motivos del Plan Director de Buenos de $1938^{14}$.

La carencia de extensiones de suelo disponible para nuevas urbanizaciones, obliga en la práctica, a operar sobre las áreas centrales de la propia ciudad ya construida mediante actuaciones de renovación, densificación y multiplicación en altura de la superficie de suelo. Gran parte de los presupuestos de las nuevas teorías arquitectónico urbanísticas del Movimiento Moderno, por no decir todas, se sustenta en su versión original en la producción de nuevo suelo urbano. Este es el caso de la Ciudad Contemporánea para Tres Millones de habitantes, el Plan Voisin y la Ciudad Radiante ${ }^{15}$. En nuestro caso particular, las mayores actuaciones se produjeron de modo parcial y aislado sobre suelo consolidado, repercutiendo sobre la morfología y la tipología urbana existente, e introduciendo nuevas formas y geometrías que se integraron con disímiles resultados en la imagen resultante.

El proyecto ganador del citado concurso, presentado por un equipo de arquitectos argentinos, es hijo de las geometría contenidas en las propuestas formuladas algunos años antes en la remodelación San Borja. También se encuentra emparentado con el Plan Director de Bogotá de Le Corbusier (1949) y del Plan de Antonio Bonet para Buenos Aires (1948). En todos ellos, la manzana tradicional se diluye en función de grandes sectores, que se ordenan en razón de funciones especializadas con sus propias dimensiones e intensidades. No debemos olvidar que nos situamos un tiempo en donde la separación de actividades urbanas era un asunto aceptado, desconociendo el debate que surgía por los efectos que producía en la ciudad. Habitación, esparcimiento, trabajo y circulación participaban en la formación de un sistema de dos tiempos para un ritmo de dos tiempos: trabajo en el centro, habitación en la periferia ${ }^{16}$.

Creada el mismo año que el Ministerio de Vivienda y Urbanismo de Chile (1966), la Corporación de Mejoramiento Urbano (CORMU), asume la misión de ...mejorar y renovar las áreas deterioradas de las ciudades mediante programas de remodelación, rehabilitación, fomento, mantención y desarrollo urbano... ${ }^{17}$. En tal misión, el año 1969 comienza la construcción de las primeras 26 torres de 20 plantas para usos residenciales consideradas en el proyecto original y otros edificios para alojar los equipamientos requeridos, en un polígono de 20 hectáreas, liberadas por la demolición del viejo hospital San Borja y de edificios privados.

14 LE CORBUSIER Op. Cit.

14 El año 1922, casi cuarenta años atrás del periodo que abarca nuestro análisis, Le Corbusier formula su primer gran modelo urbano, la Ciudad Contemporánea para tres millones de habitantes. Es ésta una ciudad al estilo de las ciudades ideales del Renacimiento: una cuadricula de calles y manzanas con una volumetría central poderosa. El príncipe renacentista, es transformado en un hombre de negocios, que se mueve a grandes velocidades por el suelo y el cielo. Es una ciudad implantada sobre un aeropuerto y un aeropuerto con su propia ciudad. Después de ello, estas utopías urbanísticas o sueños poéticos devendrán en el Plan Voisin (1925), para ser desarrollado en el centro de Paris y en la Ciudad Radiante (1929), una propuesta urbana para ser aplicada en Moscú y que terminará constituyéndose en el sustento teórico y morfológico del Plan Director de Buenos Aires de J. KURCHAN y J. FERRARI H. (1938). En todas estas propuestas, la manzana es una unidad vegetal abierta, un soporte físico que contiene edificaciones que no interiorizan ni se apropian de los espacios privados ni públicos, tal como lo expresa la manzana tradicional compacta; la calle corredor que hasta ese momento acogía la vida cotidiana de los barrios, se transforma en artería para el paso de los vehículos motorizados, que expulsa al ciudadano de sus bordes y hace desaparecer la fachada como mediador entre la vida privada y la relación pública del habitante. 
La remodelación San Borja podría ser considerada como nuestro particular Plan Voisin. La diferencia radica en que la propuesta de Le Corbusier, se instala sobre una cuadrícula base acorde con las solicitaciones de vialidad exterior y los usos más acordes con el lugar que ocupa en la ciudad. A pesar de las diferencias que se observan entre la ciudad construida y el plan de renovación, Le Corbusier tiene la suficiente inteligencia urbanística y arquitectónica para conferirle una contextualización acorde con las demandas que traen los nuevos tiempos para la ciudad, en cuanto centro de los negocios y no tanto como un soporte para el boato y la ceremonia. Propuesta que madura años más tarde en dos acciones de didácticas que entregan luces para aclararnos en nuestros problemas locales. En 1973, la construcción del primer rascacielos en el interior de París, Tour Montparnasse, generó un interesante debate público al estilo de lo que hoy son motivados por los estragos que experimenta el aparato físico y el patrimonio construido de nuestra ciudad interior, a raíz de la deficiente calidad del habitable y la cuestionable imagen urbana resultante que trae la construcción de edificios de residencias del tipo torre aislada, estilo colmena y que también son conocidos peyorativamente con el nombre de la empresa que los diseña, edifica y vende.

La segunda acción en donde madura la propuesta de Le Corbusier del 1925, adaptada a los requerimientos que imponen los 40 años que los separan y con los datos en la mano del efecto Montparnasse, es en el llamado barrio de La Défense, emplazado en el extrarradio a modo de remate exterior del eje ceremonial de París. La concentración de edificaciones en altura en un polígono de 800 hectáreas (algo así como 3 aeropuertos de Cerrillos), 25 de jardines suspendidos (¿Babilonia?), 80 de oficinas, 5 de comercio y 5 mil viviendas permiten resolver las nuevas demandas, resolver los problemas asociados con la alta intensidad de usos y evitar, también, la rotura del horizonte de la ciudad interior y la práctica desaparición de la Torre de Eiffel, uno de los principales atractores turísticos de París.

Nuestro Plan Voisin ${ }^{18}$ particular se instala sobre un suelo ganado al deterioro y que nos lleva a dudar acerca de si la solución de saneamiento elegida de gran manzana y torres exentas, carente de un tejido y de una trama urbana que la integre al conjunto mayor de barrio y ciudad, es la mejor opción. O acaso, ¿el tejido y la trama de la remodelación San Borja son el sin tejido y la sin trama? Cuestión que se transforma en la principal dificultad a la hora de pensar en una recuperación del espacio público de estas propuestas de villas a causa de la carencia de un tejido ordenador, al modo de las manzanas de la ciudad tradicional.

La Unidad Vecinal Portales (un proyecto instalado en un polígono inscrito en la Quinta Normal, en donde Brunner plantea una urbanización residencial en los años 30), se sitúa como un articulador entre la morfología de la manzana tradicional y la gran manzana de la Villa San Borja. La manzana tradicional es de naturaleza continua y horizontal, de constitución cerrada hacia el exterior y abierta hacia los patios interiores y por sí misma, organizadora de su espacialidad. La nueva manzana, es de naturaleza discontinua y abierta hacia el exterior y cerrada en su interior, de naturaleza vertical y en donde el edificio torre organiza el espacio, acogiendo los contenidos anteriormente dispuestos en forma horizontal y pareada. A diferencia de lo que sucede en la Villa San Borja, en donde el conjunto es de mayor interés que las partes, en la Villa Portales los mejores resultados son obtenidos por las tipologías edilicias, en donde es posible rastrear interesantes galerías emplazadas en pisos superiores, umbrales de acceso de peatones y vehículos, trama peatonal en segundo nivel, etc. Si la Villa San Borja es el Plan Voisin local, la Villa Portales evoca, salvando las distancias y escalas, la Unidad de

18 Proyecto para la creación de una ciudad de negocios en el mismo corazón de la ciudad según las propias palabras de Le Corbusier. Ver Hilpert, Thilo: Op. Cit. Pág. 218. 
Habitación de Marsella multiplicada a su manera en cada uno de los bloques que la integran ${ }^{19}$.

\section{Descomposición tipológica del tejido urbano}

En la ciudad interior, la carencia de extensiones de suelo disponible para nuevas urbanizaciones, obliga durante el período en estudio, a operar sobre las áreas centrales mediante actuaciones de renovación, densificación y multiplicación en altura de la superficie de suelo. Gran parte de los presupuestos de las nuevas teorías arquitectónico urbanísticas del Movimiento Moderno, por no decir todas, se sustenta en su versión original en la producción y en la actuación sobre nuevo suelo urbano.

En la ciudad interior de Santiago, por el contrario, las mayores actuaciones de urbanización son de renovación, llevándose a cabo de modo parcial y aislado sobre el casco consolidado, compacto y cerrado, repercutiendo sobre la morfología y la tipología urbana, e introduciendo nuevas formas y geometrías que se integraron con disímiles resultados en la imagen final. El esponjamiento que surge a raíz de ello, sin ninguna propuesta para el suelo libre resultante, comparece como espacios sin destinos y con una complicada legibilidad de parte del habitante, degenerando en dimensiones residuales abandonadas o siendo ocupadas como lugares de estacionamiento o almacenaje. La dimensión arquitectónica cambia de escala, pero la urbana sigue registrando, a través de la manzana, las mismas características.

En esta ciudad interior de los años 50, surge una tipología arquitectónica que tendrá sus repercusiones sobre el tejido de la manzana. Es el edificio conocido como placa y torre. Las imágenes de los primeros edificios construidos en la ciudad interior de tal tipología, se manifiestan en sus primeras plantas o en las superficies de la placa como una fachada acristalada con pequeños locales, galerías interiores y zonas de estacionamiento. En la torre se sitúan oficinas profesionales, consultas y viviendas.

Los orígenes de esta tipología arquitectónica es posible rastrearla en las formas arquitectónicas derivadas de las ordenanzas o zoning code del Regional Plan of New York, en donde el edificio iba adquiriendo altura a medida se instalaba en las áreas centrales de la ciudad y cuyo elemento placa constituía el elemento básico de la torre. En Chile, los edificios placa fueron básicamente primeros edificios comerciales. Surgen producto de las normativas que se traducían a términos arquitectónicos mediante esquemas e imágenes precisas que no permiten ni el equívoco ni la libertad del diseñador.

Tal vez el ejemplo de placa - torre más conocido sea el edificio Diego Portales, recientemente afectado por un incendio que destruyó parte importante de la placa. En donde, a diferencia de lo que encontramos en el centro de la ciudad, la torre es un elemento exento de la placa y esta como un elemento fuera de la escala de la Alameda. Sin embargo, el acierto del proyecto es el tratamiento que se le confiere en el proyecto original a las transparencias hacia el interior de la manzana. Cuestión que hubiese resuelto el efecto de desescalamiento que registra hoy el edificio. Es decir, el tejido o planimetría de la manzana se articula con ventajas con la planimetría de los edificios. Ello nos permite redirigir la atención de esta apartado hacia el tejido más que a la mención de la arquitectura.

19 Edificio de 18 plantas emplazado en la ciudad de Marsella (Francia, 1947), en él Le Corbusier vuelca ya maduras las teorías acerca de los edificios villa, entendidos como gigantescos transatlánticos, anunciados en la Ciudad Contemporánea y en la Ciudad Radiante. De este modo, elimina la vivienda unifamiliar como una unidad autárquica y única de habitación. Ver HILPERT, Thilo: Op. Cit. pp. 211. 
En el caso del edificio Diego Portales, es posible encontrar situaciones de renovación que se insertan a planimetría de manzana o tejido. En otros casos, la renovación del tejido promueve la exclusión, continuidades y rupturas, tal como lo generan los edificios de placa y torre situados en la ciudad interior. En otros casos, la renovación de los inmuebles de ciertos sectores tradicionales ha incorporado tipologías residenciales más propias de sectores del extrarradio que de zonas centrales, incluido antejardín y patio trasero. El resultado es diferente a la suburbanización de amplios sectores de la ciudad.

Atendiendo a las dramáticas vicisitudes de este ejemplar de arquitectura pública del período, no ajenas a las que han vividos otros ejemplares de la modernidad, no podemos dejar de mencionar la evocación que registra su expresión horizontal y contenida a la arquitectura de pabellón presente en la obra de Mies van der Rohe, la Neue Nationalgalerie de Berlín y la Casa Farnsworth, por ejemplo.

La inserción de nuevas tipologías arquitectónicas en el tejido consolidado, que caracteriza el período, también se hace presente con cuestionables resultados en los programas de repoblamiento llevados a cabo a lo largo de los años 90 . En tales operaciones, se renuevan los contenedores edilicios, los estilos y las intensidades, pero los elementos configurantes del espacio público siguen teniendo las mismas dimensiones y expresiones ya presentes en la ciudad. Es decir, renovación del aparato físico sin renovación urbana.

\section{Las preguntas}

La importancia del periodo radica en que la fronda urbanística, entendida como el conjunto orgánico necesario para asumir el control de las cuestiones relacionadas con la ciudad, queda estructurada en las tres primeras décadas de la segunda mitad del siglo XX. En los años 50, surge un debate académico que reflexiona acerca de los problemas que acarrea el crecimiento físico y sugiere modos de corrección. En los años 60, se aprueban los instrumentos, se fundan las instituciones públicas y se formulan los proyectos que requiere el desarrollo urbano. En los años 70, se llevan a cabo las principales obras urbanas del período.

El problema es que no siempre se ha tenido en cuenta esta tripleta básica, necesaria para darle un sentido a la acción urbanística y optar a resultados positivos cuando se actúa sobre la ciudad: debate, institución y proyecto.

Debemos entender que la construcción de la ciudad es un tema público continuo y de primera necesidad. Al final, más que conclusiones, nos asaltan preguntas acerca de las oportunidades y ocasiones que se ha da la sociedad para transformar el aparato físico en donde desarrolla sus actividades. La mayoría de las veces los resultados quedan supeditados a las circunstancias que rodean los planes, proyectos y programas que se formulan para encauzar los recursos y ordenar los anhelos. Pero, en no pocas ocasiones las circunstancias políticas, económicas y sociales son de mayor rotundidad que los propios contenidos de los documentos.

En los debates, propuestas y obras que se hacen presente durante el periodo en estudio, queda en evidencia las veces que éstos y éstas comparecen como estrategias carentes de un proyecto urbano que contextualice los impactos positivos que se derivan de las mismas y corrija las alteraciones que se producen por su ejecución. Con ello se desaprovechan las oportunidades que surgen para transformar estos proyectos y estrategias en operaciones detonantes de mejora de los sectores en donde se emplazan. En urbanismo y en urbanística la obra no sólo es lo que debe ser, sino también algo más. Y ese algo más es su incidencia en el modelo territorial, en la estructura urbana, en la morfología y la tipología del 
espacio y que son los elementos que influyen en la percepción, en la legibilidad y ocupación del suelo que hace la sociedad.

En los años 60 y 70, muy cerca de nosotros, hay mucha materia desconocida que es necesario explorar con el fin de valorar un pensamiento y un hacer que más allá de sus efectos, algunos perversos, entrega luces para construir el futuro. Muchas veces, estos efectos no provienen directamente de la norma o de la forma, sino de las limitaciones que registran las instituciones, la sociedad al fin y al cabo, para disponer de los recursos legales, administrativos y económicos necesarios para que la construcción continua de la ciudad valore permanencias y elementos invariables sobre los cuales asentar acciones de renovación.

La posterior reacción postmodernista de fines de los años $80^{20}$, transforma y debilita los intentos de valorar en su justa apreciación un período sustancioso en aportes y generoso en cambios, desconociendo que las más de las veces, los conflictos surgen motivados a veces por la aplicación parcial o a medias o tal como sigue sucediendo hoy en día, y a veces por la falta de sistemas de gestión que coordinen las propuestas con los recursos.

20 Entendemos por reacción postmodernista a aquella que en asuntos urbanísticos, lleva a la anulación de los límites urbanos y el práctico abandono de la planificación y sus determinaciones a través del Decreto 420 (1975). En términos arquitectónicos, esta reacción es llevada a cabo por un grupo de arquitectos reunidos en torno a la Revista ARS. 


\section{Bibliografía temática}

\section{Morfología y Tipología Urbana}

CASTEX, Jean et alters. Formes urbaines: de l'ilot a la barre. Dunod, Paris, 1980.232 pp.

PANERAIX, Philippe et alters. Elementos de análisis urbano. Colección Nuevo Urbanismo No 42, IEAL. Madrid, 1983, 280 pp.

SOLA-MORALES, Manuel de. Las formas del crecimiento urbano. Edicions UPC. Barcelona, 1997, $197 \mathrm{pp}$.

\section{Movimiento Moderno}

HILPERT, Thilo. La ciudad funcional: Le Corbusier y su visión de la ciudad. Colección Nuevo Urbanismo No 41, IEAL, Madrid, 1983, 490 pp.

LE CORBUSIER. Precisiones respecto a un estado actual de la arquitectura y el urbanismo. Edit. Poseidón, Barcelona, 1978, 296 pp.

\section{Planificación Regional}

TERÁN, Fernando de. Madrid: Ciudad Región. Entre la ciudad y el territorio en la segunda mitad del siglo XX. Comunidad de Madrid, Madrid, 1999, 157 pp.

Violich, Francis. Cities of Latin América. Reinhold, New York, 240 pp.

BOLETÍN INFORMATIVO No 34. Segunda y Tercera Etapa Seminario del Gran Santiago. Universidad de Chile, Santiago, 1958, 323 pp.

\section{Transporte y Vialidad}

AUCA N 27. Transporte Urbano. Santiago de Chile, 1974.

CONSEJERÍA DE TRANSPORTES. Movilidad y territorio en las grandes ciudades: el papel de la red viaria. Comunidad de Madrid y MOTMA. Madrid, 1993, 294 pp.

MUMFORD, Lewis. La carretera y la ciudad. Emecé Editores. Buenos Aires, 1966, 320 pp.

PARROCHIA, Juan. Santiago en el Tercer cuarto del siglo XX. FAU - UCH. Santiago de Chile, 1979, Ed. Departamento de Urbanismo de la U. de Chile, 238 pp.

\section{Urbanismo de Santiago de Chile}

AUCA N 37. Santiago: Metrópolis en crisis. Santiago de Chile, 1979.

C.A. No 81. X Bienal de Arquitectura y Urbanismo. Colegio de Arquitectos de Chile. Santiago, 1995.

D.O.M. Santiago Poniente: desarrollo urbano y patrimonio. Ilustre Municipalidad de Santiago. Santiago de Chile, 2000, 216 pp.

D.O.M. Santiago sur poniente: barrio universitario, desarrollo urbano y patrimonio. Ilustre Municipalidad de Santiago. Santiago de Chile, 2004, 134 pp.

PAVEZ, María Isabel. En la ruta de Juan Parrochia Beguin. FAU - UCH., Santiago de Chile, Ed. Vicerrectoría de Investigación y Desarrollo, D. Urbanismo, U. de Chile., 2003, 320 pp. 